\title{
Mutants of Bacillus subtilis Defective in Protein Export
}

\author{
By VESA P. KONTINEN* AND MATTI SARVAS \\ National Public Health Institute, Mannerheimintie 166, SF-00280 Helsinki 28, Finland
}

(Received 10 November 1987; revised 18 March 1988)

\begin{abstract}
We have isolated a set of strains with mutations (designated prs) that decrease secretion of $\alpha$-amylase and have a pleiotropic effect on secretion of other exoproteins. The seven mutants were selected in a strain of Bacillus subtilis which overproduces $\alpha$-amylase due to the presence of an $\alpha$-amylase gene on a multicopy plasmid. The mutations were mapped to four different chromosomal loci. The phenotype of the mutants, especially their pleiotropic effects and the accumulation of $\alpha$-amylase precursor, indicated that they have defects in the mechanism of protein export. Double mutants with certain pairwise combinations of mutations in different loci had additive effects on secretion, suggesting that these prs genes encode different components of the secretion pathway.
\end{abstract}

\section{INTRODUCTION}

The export of proteins requires several cellular components, both membrane-bound and cytoplasmic, that recognize the export signal(s) and direct the protein across the membrane (Walter, 1987). Several components of the export machinery are well characterized in eukaryotic cells. They include signal peptidases (Evans et al., 1986), the signal recognition particle (SRP) (Warren \& Dobberstein, 1978; Walter \& Blobel, 1981), SRP receptor (Gilmore et al., 1982; Meyer et al., 1982), the signal sequence receptor (Wiedmann et al., 1987) and ribophorins (Kreibich et al., 1978). By contrast, only the signal peptidases are well characterized in Escherichia coli (Wolfe et al., 1983; Innis et al., 1984) whereas the involvement of other cellular components is only indicated by mutations affecting protein export. Although some of the genes, e.g. $\sec A$ (Oliver \& Beckwith, 1981) and prlA (Emr et al., 1981), defined by these mutations are well characterized, their function in secretion is still largely unknown. The nature of the mutations, conditionally lethal or suppressor, has handicapped functional studies (see Silhavy et al., 1983). Furthermore, all these mutations affect early steps of export, probably due to the constraints dictated by the powerful selection needed to find them. It is thus possible that many genes involved in the export of proteins in $E$. coli have remained undetected.

Genetic studies on protein export in Bacillus can be expected to demonstrate new types of genes affecting protein export. $B$. subtilis secretes true exoproteins which, in contrast to most major exported proteins of $E$. coli, are not components of the cell envelope. The fact that many Bacillus species are devoid of exoproteins indicates that exoproteins are not indispensable in Bacillus and suggests that mutations preventing secretion need not be lethal. On the other hand, the large amount of protein secreted by $B$. subtilis (Palva, 1982) suggests easy screening methods for indentifying mutants with either complete or partial defects in secretion.

Against this background we set out to isolate mutants of $B$. subtilis defective in protein secretion. Our approach was to start from a strain of $B$. subtilis that carries the structural gene of $\alpha$-amylase on a multicopy plasmid and thus secretes large amounts of the protein. We screened for decreased secretion of the $\alpha$-amylase, and analysed the mutants thus obtained by biochemical and genetical methods.

Abbreviation: NNG, $N$-methyl- $N$-nitroso- $N^{\prime}$-nitroguanidine. 


\section{METHODS}

Bacteria, phages and plasmids. The $B$. subtilis strains used in mutagenesis experiments and in genetic crosses are listed in Table 1. Mapping experiments were done with phage PBS1; recipient strains were strains KIT1 through KIT9 (Dedonder et al., 1977), obtained from the Bacillus Genetic Stock Center (BGSC). Plasmid pKTH10 is a derivative of pUB1 10 (Palva, 1982) with a $2 \cdot 3 \mathrm{~kb}$ insert from $B$. amyloliquefaciens. The insert contains the gene for secreted $\alpha$-amylase. pKTH6 is an analogous derivative of pUB1 10 with an insert at the EcoRI site (about $5.4 \mathrm{~kb}$ ) containing the penP (lipopenicillinase) gene of $B$. licheniformis.

Media and growth conditions. Modified L-broth containing 0.5\% $\mathrm{NaCl}$ (Sibakov et al., 1983) was supplemented with $2 \%(\mathrm{w} / \mathrm{v})$ soluble starch (Difco) for experiments to determine the secretion kinetics of different exoenzymes and with $5 \%(\mathrm{w} / \mathrm{v})$ starch and $5 \%(\mathrm{w} / \mathrm{v})$ agar to make starch plates for screening of mutants defective in $\alpha$-amylase secretion. In transformation and transduction experiments Spizizen minimal medium (SMS) (Anagnostopoulos \& Spizizen, 1961) and agar, antibiotic medium 3 (17.5 $\mathrm{g}^{-1}$, Difco) and TBAB (tryptose blood agar base) agar (Difco) were used. Sporulation frequency was determined in NSM (nutrient sporulation medium) broth (Vasantha \& Freese, 1980). All cultures were incubated at $37^{\circ} \mathrm{C}$; liquid cultures were aerated vigorously.

Growth was determined by measuring culture density in a Klett-Summerson colorimeter with a no. 66 filter.

Mutagenesis and screening of mutants. Bacteria from $10 \mathrm{ml}$ of exponential culture (IH6160 in L-broth) were

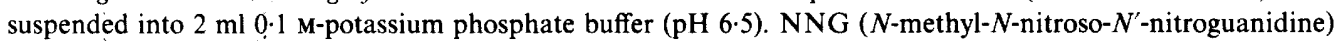
was added to a final concentration of $0.1 \mathrm{mg} \mathrm{m}^{-1}$, which killed about $99 \%$ of the bacteria. After incubation with shaking for $30 \mathrm{~min}$ at $37^{\circ} \mathrm{C}$, cells were harvested, washed twice with the above buffer and suspended into $1 \mathrm{ml}$ of the same. Portions $(0.1 \mathrm{ml})$ of this suspension were added to $10 \mathrm{ml} \mathrm{L}$-broth, grown for $4 \mathrm{~h}$ and appropriate dilutions plated onto starch plates supplemented with kanamycin $\left(10 \mu \mathrm{g} \mathrm{ml}^{-1}\right)$. Plates were incubated for $16 \mathrm{~h}$ at $37^{\circ} \mathrm{C}$ and then transferred to $4^{\circ} \mathrm{C}$ for screening mutants defective in $\alpha$-amylase secretion. A clear halo developed in about $6 \mathrm{~h}$ around $\alpha$-amylase-positive colonies. Colonies with a decreased halo diameter were picked up as putative secretion mutants. The secretion defect was confirmed by assaying $\alpha$-amylase production in L-broth. Before any further analysis the mutated gene was transformed either to strain IH6157 ( is $^{+}$selection) or IH6513 (thr ${ }^{+}$selection) to exclude multiple mutations. The frequency of auxotropic mutants was about $10 \%$ in all of the mutagenesis experiments.

Transformation and transduction. Transformation was done as described by Gryczan et al. (1978) and transformants selected on SMS agar. PBS1 lysates were made as follows. A mutant strain in a soft agar lawn on TBAB plates was infected with PBS1 to obtain semiconfluent lysis. The soft agar layer was scraped off into a small volume of antibiotic medium 3 , chloramphenicol was added $\left(5 \mu \mathrm{g} \mathrm{ml}^{-1}\right)$ and the suspension was incubated at $48^{\circ} \mathrm{C}$ overnight without aeration. After centrifugation $(10000 \mathrm{~g}, 10 \mathrm{~min})$ the lysate was passed through a Millipore filter $(0.45 \mu \mathrm{m})$ and stored at $4{ }^{\circ} \mathrm{C}$. This phage preparation was used for transduction as described by Young \& Wilson (1974) with slight modifications.

Enzyme assays. $\alpha$-Amylase was assayed using the Phadebas amylase test (Pharmacia). Samples were incubated for $2 \mathrm{~h}$ at $37^{\circ} \mathrm{C}$ in $4.2 \mathrm{ml}$ water containing one dispersed Phadebas pellet, after which $0.5 \mathrm{ml} \mathrm{NaOH}$ was added to terminate the reaction. After filtration through Whatman no. 1 filter paper, the $A_{600}$ of the filtrate was measured. The results were expressed as $\mu \mathrm{g}$ enzyme $\mathrm{ml}^{-1}$ (commercially available $\alpha$-amylase of $B$. amyloliquefaciens (Sigma) was used as standard). Protease activity was determined as described by Sibakov et al. (1983). One enzyme unit (U) causes an absorbance change of $0.1 A_{595}$ unit h-1 at $37^{\circ} \mathrm{C}$. Penicillinase was assayed using nitrocefin as described by Simons et al. (1978); the results were expressed as $\mu \mathrm{g}$ enzyme $\mathrm{ml}^{-1}$.

Sporulation frequency. This was determined in NSM-broth as described by Sibakov (1986).

Motility. The motilities of different strains were compared on L-broth plates supplemented with $0.4 \%$ agar by placing a small drop of exponentially growing culture into the centre of the plate and measuring the spread of bacteria after incubation at $37^{\circ} \mathrm{C}$ overnight.

SDS-PAGE and immunoblotting. These were done as described by Sarvas \& Nurminen (1985).

Isolation of membranes. Membrane samples were prepared by sonic disruption of lysozyme-treated cells followed by centrifugation at $100000 \mathrm{~g}$ for $1 \mathrm{~h}$ at $4{ }^{\circ} \mathrm{C}$ (Kallio et al., 1986). The pellet was resuspended to a volume onehundredth that of the culture the bacteria were derived from.

Reagents. NNG was purchased from Koch-Light, Phadebas amylase test and Staphylococcal protein A from Pharmacia Diagnostics, $\alpha$-amylase of $B$. amyloliquefaciens from Sigma, and nitrocefin from Glaxo.

\section{RESULTS}

\section{Isolation of mutants with decreased secretion of $\alpha$-amylase}

Strain IH6160, a hyperproducer of $\alpha$-amylase due to multiple copies of plasmid pKTH10 (see Table 1), was mutagenized with NNG and plated onto starch plates. About 40000 colonies were screened for decreased secretion of $\alpha$-amylase, and several were found that had smaller haloes around the colony. In order to determine whether the mutations were located on the plasmid or 
Table 1. Bacillus subtilis strains

\begin{tabular}{|c|c|c|}
\hline Strain & $\begin{array}{l}\text { Relevant genotype/ } \\
\text { plasmid carried** }\end{array}$ & Parent/source/reference \\
\hline IH6064 & metB5 sacA321 amyRI & Sibakov et al. (1983) \\
\hline IH6090 & hisAl metBS sacA32I amyRl & IH6064 \\
\hline IH6131 & IH6090(pK TH6) & IH 6090 \\
\hline IH6157 & IH6090(pKTHI0) & IH6090 \\
\hline IH6160 & IH6064(pKTH10) & IH6064 \\
\hline IH6509 & QB934(pKTH10) & QB934 \\
\hline IH6513 & QB917(pKTH10) & QB917 \\
\hline IH6531 & glyB1 hisAI trpC2 (pKТН10) & IH $6513 \dagger$ \\
\hline IH6532 & QB943(pKTH10) & QB943 \\
\hline QB917 & his $A 1$ thr-5 trpC2 & $1 \mathrm{~A} 10$ in $\mathrm{BGSC} \ddagger$ \\
\hline QB934 & tre- 12 metC 3 glyB 133 trp C2 & $1 \mathrm{~A} 5$ in $\mathrm{BGSC}$ \\
\hline QB943 & pyrDI IlvAl thyAl thyB 1 trpC 2 & $1 \mathrm{~A} 6$ in $\mathrm{BGSC} \S$ \\
\hline
\end{tabular}

\footnotetext{
${ }^{*}$ pKTH6 is a derivative of pUB110 with an insert of the penP gene from $B$. ticheniformis. pKTH10 is a derivative of pUB 110 with an insert of the $\alpha$-amylase gene from $B$. amyloliquefaciens.

$\dagger$ Transformant with DNA from QB934.

$\ddagger$ BGSC, Bacillus Genetic Stock Center, The Ohio State University, Department of Biochemistry, 484 West 12th Avenue, Columbus, Ohio 43210, USA.

$\S$ Received from F. Kunst, Institut Pasteur, 28, Rue du Dr Roux, 75724 Paris Cedex 15, France.
}

on the chromosome, the plasmid was transferred from all these mutants to a plasmidless strain, IH6064. In only one mutant was there complete loss of $\alpha$-amylase, and this coincided with loss of the plasmid, concordant with the described stability of pKTH10 (Vehmaanperä \& Korhola, 1986). In about 30 mutants the decreased secretion of $\alpha$-amylase was co-transferred with the plasmid; these mutated plasmids were presumed to have mutations in the structural gene or control region of $\alpha$-amylase and were not studied further. In seven cases the transformants appeared to secrete as much $\alpha$-amylase as IH6160, as judged by the size of the halo, implying that the mutations in the original strains were chromosomal. These protein secretion (prs) mutations were transformed into new host strains IH6157 or IH6513 (both carrying pKTH10), to exclude as far as possible the effects of multiple mutations.

\section{Growth and secretion of exoproteins in the prs mutants}

Decreased $\alpha$-amylase secretion in the prs mutants was not caused by a decreased growth rate. All mutants and their parents had identical growth rates and the same maximal growth in Lbroth supplemented with $2 \%$ soluble starch, with variation between several experiments of less than $10 \%$.

The exoamylase production of mutant prs-3 is shown and compared to the parent strain, IH6157, in Fig. 1(a). In this mutant the concentration of exoamylase did not exceed the detection threshold before the early stationary phase (approx. $8 \mathrm{~h}$ ). At this point the amount of exoamylase was about $3 \%$ of that in the parent strain, and in the later stationary phase it was only about $1 \%$ of the parental level.

To compare different mutants we therefore used the amount of the $\alpha$-amylase in the culture supernatant in the early stationary phase (Table 2 ). In the seven mutants this amount varied between 4 and $28 \mu \mathrm{g} \mathrm{ml}^{-1}$ or $2-14 \%$ of that in the parent. In the late stationary phase the relative amount of exoamylase further decreased to below $3 \%\left(<45 \mu \mathrm{g} \mathrm{ml}^{-1}\right)$ except in prs-33, in which it was about $15 \%$.

Because a mutation affecting the export machinery is likely to cause defects in the export of several exoenzymes, we also determined the exoprotease activity of the prs mutants. Fig. $1(b)$ shows the kinetics of exoprotease production in prs-3 and Table 2 shows the level of exoprotease in the early stationary phase in other prs mutants. The production of exoprotease was decreased in all prs mutants compared to the parent, but the decrease was comparatively less (to $18-62 \%$ of the parent) than the decrease of $\alpha$-amylase (to $2-14 \%$ ). 


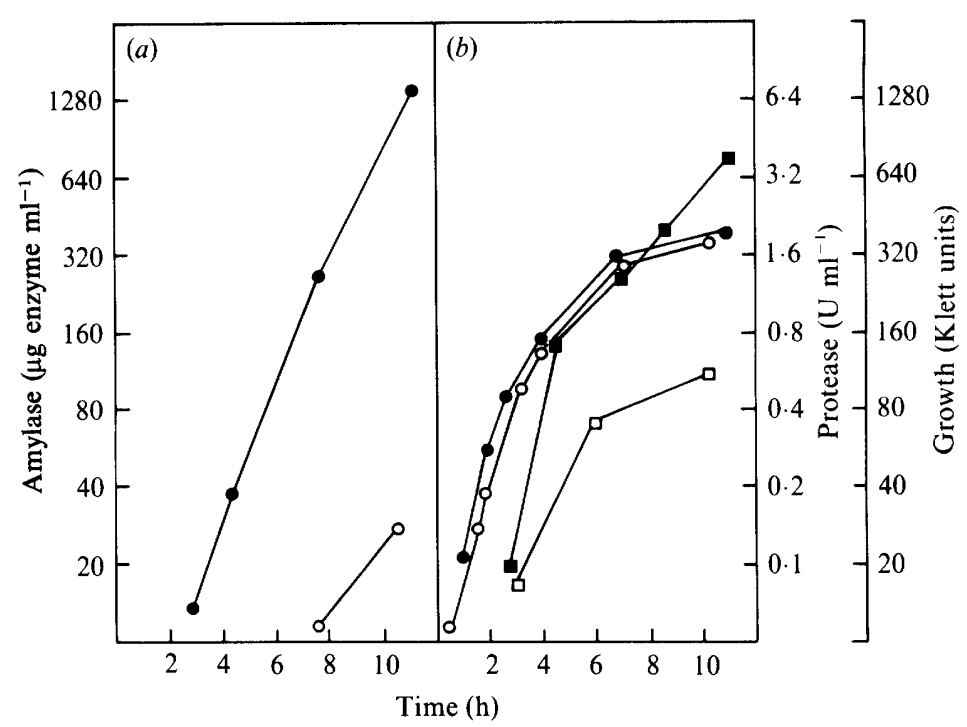

Fig. 1. Secretion of $\alpha$-amylase and protease by IH6157 and its prs-3 derivative IH6480. (a) $\alpha$-Amylase: 0 , wild-type; $\bigcirc$, prs-3. (b) Growth rate: 0 , wild-type; $\bigcirc$, prs-3. Protease: $\square$, wild-type; $\square$, prs-3.

Table 2. Exoenzymes in the culture supernatant of prs mutants

\begin{tabular}{|c|c|c|c|c|c|c|}
\hline \multirow[b]{3}{*}{$\begin{array}{l}\text { Control } \\
\text { strain . . }\end{array}$} & \multicolumn{2}{|c|}{$\alpha$-Amylase ${ }^{*}$} & \multicolumn{2}{|c|}{ Protease* } & & \\
\hline & Plasmid-coded & Chromosomally & With & Without & \multicolumn{2}{|c|}{ Penicillinase $\dagger$} \\
\hline & $\begin{array}{l}\text { IH6157 or } \\
\text { IH6513 }\end{array}$ & $\begin{array}{l}\text { encoded } \\
\text { IH6064 or } \\
\text { QB917 }\end{array}$ & $\begin{array}{l}\text { pKTH10 } \\
\text { IH6157 or } \\
\text { IH6513 }\end{array}$ & $\begin{array}{l}\text { pK TH10 } \\
\text { IH6064 or } \\
\text { QB917 }\end{array}$ & $\begin{array}{l}\text { Cell-bound } \\
\text { IH6131 }\end{array}$ & $\begin{array}{l}\text { Secreted } \\
\text { IH6131 }\end{array}$ \\
\hline $\begin{array}{l}\text { nzyme } \\
\text { ctivity }\end{array}$ & $210 \mu \mathrm{g} \mathrm{ml}^{-1}$ & $0.2 \mu \mathrm{g} \mathrm{ml}^{-1}$ & $2 \mathrm{U} \mathrm{ml}^{-1}$ & $8 \mathrm{U} \mathrm{ml}^{-1}$ & $2 \cdot 2 \mu \mathrm{g} \mathrm{ml}^{-1}$ & $0.3 \mu \mathrm{g} \mathrm{ml}^{-1}$ \\
\hline
\end{tabular}

Mutant

Percentage of the enzyme activity of the control:

prs-3

prs-29

prs -40

prs-26

prs -13

prs-33

prs-11

$\begin{array}{rrr}51 & 18 & 83 \\ 72 & 23 & 67 \\ 70 & 33 & 81 \\ 84 & 31 & 93 \\ 88 & 62 & 100 \\ 51 & 30 & 32 \\ 100 & 53 & 62\end{array}$

$\begin{array}{rrr}83 & 100 & 100 \\ 67 & 100 & 100 \\ 81 & 100 & 100 \\ 93 & 67 & 22 \\ 100 & 75 & 28 \\ 32 & 58 & 130 \\ 62 & 5 & 1200\end{array}$

* Determined in the early stationary phase $(6 \mathrm{~h}$ after the culture density reached $100 \mathrm{Klett}$ units).

$\dagger$ Determined in late-exponential-phase cultures (200 Klett units). Cell-bound penicillinase was from intact whole cells.

All the mutant strains carried the plasmid pKTH10 and were therefore hyperproducers of $\alpha$ amylase in spite of the decreased level of the enzyme. Since it is possible that the protein export machinery is saturated by high levels of $\alpha$-amylase secretion (Sibakov et al., 1983), we determined the production of exoproteases and exoamylase coded by the chromosomal amyE gene by the mutant strains in the absence of pKTH10. Table 2 shows that the effect of the prs mutations under these conditions was much less.

\section{Effect of the prs mutations on the export of lipopenicillinase}

The lipopenicillinases form a unique class of Bacillus exoproteins which, unlike other exoproteins, involve a membrane-bound form from which the exopenicillinase is proteolytically released. Furthermore, at least one component of the secretory machinery, the lipoprotein signal 


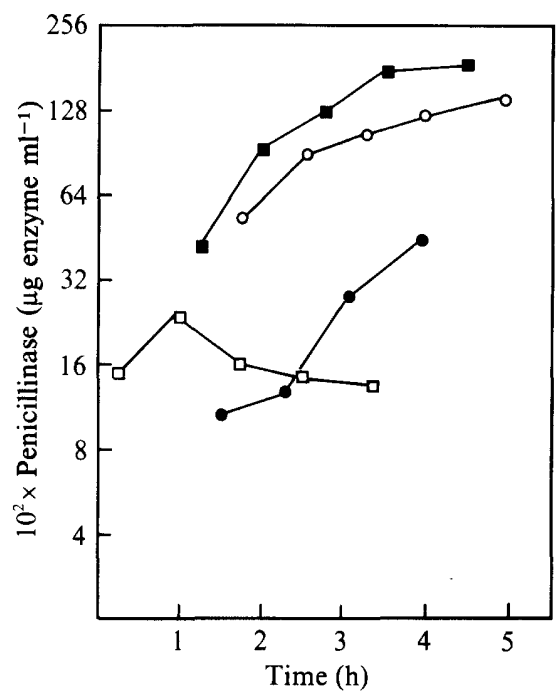

Fig. 2. Secreted (in culture supernatant) and cell-bound (in intact whole cells) penicillinase of prs

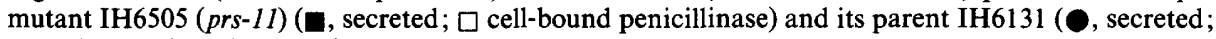
$\mathrm{O}$, cell-bound penicillinase).

peptidase, is specific for lipoproteins. It was therefore of interest to study the effect of the prs mutations on this secretory pathway.

The plasmid pKTH6, a derivative of pUB110 carrying the lipopenicillinase gene penP of $B$. licheniformis, was transformed into the set of prs mutants. Table 2 shows the amount of membrane-bound penicillinase and exopenicillinase in these strains in the late-exponential phase of growth. The ratio of the membrane-bound and exopenicillinase remained about $7: 1$ in the non-mutated parent strain throughout the exponential phase as shown previously (Imanaka et al., 1985). The prs mutants exhibited two types of changes to this pattern. In prs-26 and prs-13 the level of exopenicillinase was decreased to about $25 \%$ of that in the parent, with a lesser decrease of the membrane-bound form. In prs- 11 there was a change in the opposite direction, so that essentially all the penicillinase was in the form of exopenicillinase; the total amount of penicillinase synthesized was also slightly higher than in the parent (Fig. 2). The mutation prs-33 had very little effect on lipopenicillinase secretion despite its effect on the other exoenzymes. The remaining three prs mutations had no effect on penicillinase (Table 2).

\section{Effects of the prs mutations on sporulation and other phenotypic properties}

Decreased production of proteases is frequently found in sporulation mutants (Piggot, 1985). We therefore determined the sporulation frequency of the prs mutants (Table 3 ). In one mutant (prs-33) there were no spores. Some other mutants showed a slightly decreased frequency of sporulation, but not to the extent seen in most spo mutants (Piggot, 1985).

Mutants prs-29 and prs-33 showed changes of colony morphology (Table 3). prs-29 caused a clearly altered colony morphology (very small raised colonies) when the mutant carried pKTH10 and therefore produced large amounts of $\alpha$-amylase, but the colony size was normal if pKTH10 was replaced by pKTH6, which produces penicillinase at a much lower level than pKTH10 produces $\alpha$-amylase. Three mutants (prs-13, prs-26 and prs-33) were nontransformable.

\section{Genetic mapping}

The prs mutations were mapped by transduction with phage PBS1 and transformation (Table 4). Five of the seven prs mutations mapped very close to $g l y B$ (cotransfer frequencies by transduction about $90 \%$ ) with no $(<5 \%)$ linkage with metC or trpC. Interestingly, prs- 13 and prs26 had a tighter linkage (about $100 \%$ ) to $g l y B$ than did the other $g l y B$-linked prs mutations, 
Table 3. Some phenotypic properties of prs mutants

The properties (except transformability) were determined in strains carrying pKTH10.

\begin{tabular}{|c|c|c|c|}
\hline Strain & Mutation & $\begin{array}{l}\text { Sporulation } \\
\text { frequency* }\end{array}$ & Other properties \\
\hline IH6513 & Wild-type & $2.0 \times 10^{8}$ & \\
\hline IH6525 & prs-3 & $0.5 \times 10^{8}$ & \\
\hline IH6527 & prs-29 & $1.5 \times 10^{7}$ & Decreased colony size $\dagger$ \\
\hline IH6537 & prs -40 & $1 \cdot 3 \times 10^{8}$ & \\
\hline IH6521 & prs -26 & $2.0 \times 10^{5}$ & Not transformable \\
\hline IH 6522 & prs -13 & $2.0 \times 10^{6}$ & Not transformable $\ddagger$ \\
\hline IH6529 & prs-33 & 0 & $\begin{array}{l}\text { Not transformableł; } \\
\text { decreased motility; } \\
\text { 'rough' colony }\end{array}$ \\
\hline IH 6520 & prs-11 & $0.5 \times 10^{5}$ & \\
\hline
\end{tabular}

* No. of spores determined as described in Methods.

+ Colonies were of nearly normal size if there was no pKTH10 in the mutant strain.

$\ddagger$ The mutant was transformed with pK TH10. The frequency of transformation was less than $10^{-4}$ of that of the parent.

\section{Table 4. Mapping of prs mutations}

prs mutations were mapped with both transduction and transformation. Contransfer of prs with a linked genetic marker is shown as percentage of transformants. In all crosses more than 50 colonies were screened for prs.

\begin{tabular}{|c|c|c|c|c|c|}
\hline \multicolumn{2}{|c|}{ Donor } & \multirow[b]{2}{*}{ Recipient* } & \multicolumn{3}{|c|}{ Selected marker and linkage $(\%)$} \\
\hline Strain & Mutation & & Marker & Transduction & Transformation $\dagger$ \\
\hline IH6480 & prs -3 & IH6509 & glyB & 92 & 38 \\
\hline IH6482 & prs -29 & IH6509 & glyB & 95 & 63 \\
\hline IH6484 & prs -40 & IH6509 & glyB & 88 & 56 \\
\hline IH6491 & prs -26 & IH6509 & glyB & $>95$ & 72 \\
\hline IH6497 & prs -13 & IH6509 & glyB & $>95$ & 81 \\
\hline IH6483 & prs $-33 \ddagger$ & IH6532 & pyrD & 29 & ND \\
\hline IH6489 & prs -11 & IH6513 & his $A$ & 93 & 89 \\
\hline
\end{tabular}

suggesting the presence of two separate prs loci in this area. By analogous reasoning prs-33 was localized in the pyrD-thy $A$ region, and prs- 11 near his $A$ (about $90 \%$ linkage). Transformation confirmed all the linkages with $g l y B$ and his $A$ loci. The transformation data also confirmed the tighter linkage with $g l y B$ of prs-13 and prs-26. Thus the seven mutants indicate the presence of at least four genes (loci) involved with protein secretion.

\section{Recombinants with two prs mutations}

To investigate the possible synergistic effect of prs mutations at the four separate loci, the hislinked prs-11 and the pyrD-thyA-linked prs-33 were recombined with the rest of the mutations as shown in Fig. 3. The amount of $\alpha$-amylase secreted by each of the constructs was determined in the early stationary phase of growth (Table 5). Both prs- 11 and prs-33 alone caused a similar moderate decrease of $\alpha$-amylase (to about $10 \mu \mathrm{g} \mathrm{ml}^{-1}$ and $6 \mu \mathrm{g} \mathrm{ml}^{-1}$ respectively). However, their combination with the other prs mutations had very different effects. prs- 11 combined with most of the other prs mutants had hardly any additional effect. The only exception was prs-33: the level of $\alpha$-amylase in the double mutant prs-11 prs-33 was only $1.4 \mu \mathrm{g} \mathrm{ml}^{-1}$. On the other hand, 
(a)

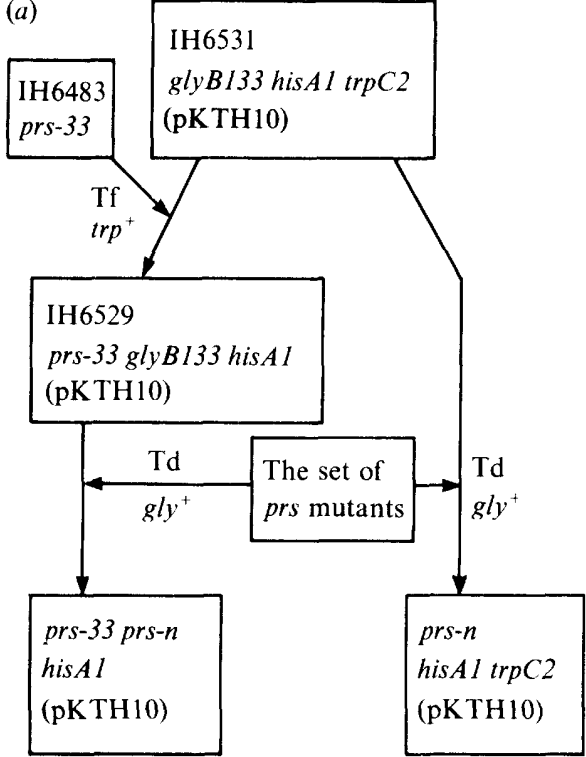

SET A

SET B

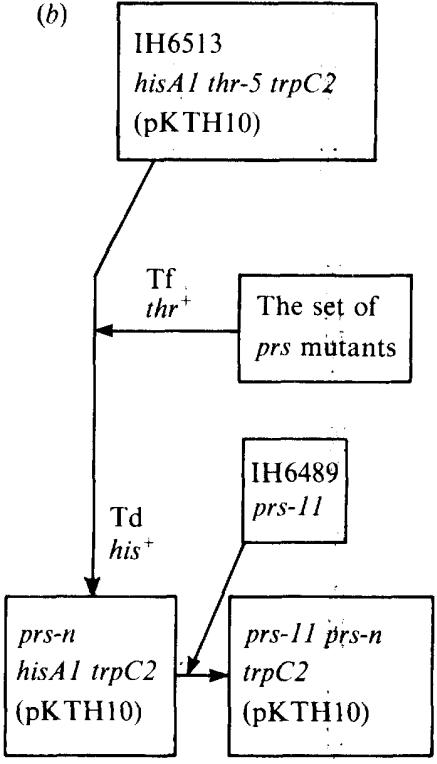

SET C

SET' D

Fig. 3. Construction of recombinants with two prs mutations. The his-linked prs- 11 and the pyrD-thy $A$ linked prs-33 were recombined with the other prs mutations as indicated. 'prs- $n$ ' denotes the set of prs mutants as in Table 5. Tf, transformation; Td, transduction; the marker used for selection is indicated.

Table 5. Secretion of $\alpha$-amylase by double prs mutants

The set of prs mutations were recombined with prs- 11 and prs-33 to construct double mutants. All double mutants were made in strain IH6513 or its derivative (IH6531) as described in Fig. 3. $\alpha$-Amylase is expressed as $\mu \mathrm{g}$ enzyme per $\mathrm{ml}$ of culture determined in the early stationary phase of growth.

\begin{tabular}{|c|c|c|c|c|c|}
\hline $\begin{array}{c}\text { First } \\
\text { mutation }\end{array}$ & $\begin{array}{l}\text { Second } \\
\text { mutation }\end{array}$ & None* & prs-33† & None & prs-11§ \\
\hline prs-3 & & $0 \cdot 1$ & 0.03 & $0 \cdot 3$ & $0 \cdot 3$ \\
\hline prs-29 & & 0.7 & 0.05 & 0.5 & 0.3 \\
\hline prs -40 & & $1 \cdot 1$ & $0 \cdot 2$ & $1 \cdot 1$ & $0.9 \|$ \\
\hline prs -26 & & 1.0 & 1.5 & $3 \cdot 1$ & $1 \cdot 2$ \\
\hline prs -13 & & 0.9 & $1 \cdot 5$ & $2 \cdot 4$ & $1 \cdot 1$ \\
\hline prs -33 & & - & - & 5.7 & $1 \cdot 4 \|$ \\
\hline prs -11 & & $9 \cdot 8$ & $1 \cdot 4$ & - & - \\
\hline None & & - & 6.0 & - & $10 \cdot 0$ \\
\hline
\end{tabular}

* Derivatives of IH6531 (set B, Fig. 3).

† Derivatives of IH6531 (set A, Fig. 3).

$\ddagger$ Derivatives of IH6513 (set C, Fig. 3).

$\S$ Derivatives of IH6513 (set D, Fig. 3).

$\|$ The host of this double mutant is IH6531.

prs-33 together with prs-3, prs-29 or prs-40 decreased the very low level of $\alpha$-amylase of these mutants $\left(0 \cdot 1-0 \cdot 7 \mu \mathrm{g} \mathrm{ml}^{-1}\right)$ even further, down to $7-30 \%$ of that in the single mutant. However, it had no effect on prs-13 and prs-26, the mutations with very tight linkage to glyB.

Because the mapping data indicated at least two separate groups of mutations linked to gly $B$ (Table 4), we also combined mutations of both groups as described in Table 6 . Determination of $\alpha$-amylase of the double mutants (Table 6) showed two very different phenotypes. prs-40 prs-26 produced slightly less $\alpha$-amylase than each of the single mutants. No double mutants combining 


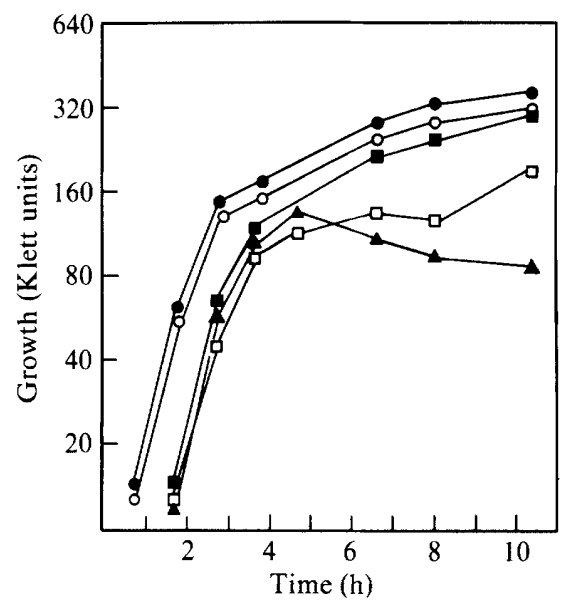

Fig. 4. Growth rates of a set of prs mutants linked to glyB and two recombinants of them (see Table 6). , IH6521 (prs-13); O, IH6522 (prs-26); ם, IH6527 (prs-29); $\square$, IH6550 (prs-29 prs-26); $\Delta$, IH6551 (prs-29 prs-13).

\section{Table 6. Secretion of $\alpha$-amylase by recombinants with two glyB-linked prs mutations}

Construction of recombinants with two $g l y B$-linked prs mutations was based on the presence of two groups of prs mutations with different degrees of cotransformational linkage to gly $B$ (see Table 4). In the first step, strain IH6531 (a Gly derivative of strain IH6513) was transformed with DNA from prs mutants weakly linked to $g l y B$. His ${ }^{+}$transformants were selected and among them prs-gly recombinants were screened. These single mutants were then transformed with DNA from mutants tightly linked to $g l y B$ by selecting Gly ${ }^{+}$tranformants. These recombinants were screened on starch plates by looking for decreased $\alpha$-amylase secretion. Secretion of $\alpha$-amylase by double mutants, and the corresponding single mutants, was determined in liquid culture in the exponential phase (culture density 100 Klett units) and in the early stationary phase (6 h later).

\begin{tabular}{|c|c|c|}
\hline \multirow[b]{2}{*}{ Mutation } & \multicolumn{2}{|c|}{$\begin{array}{l}\alpha \text {-Amylase }\left(\mu \mathrm{g} \mathrm{ml}^{-1}\right) \text { in the culture } \\
\text { supernatant }\end{array}$} \\
\hline & Exponential phase & Early stationary phase \\
\hline prs-13 & $0 \cdot 2$ & $11 \cdot 0$ \\
\hline$p r s-26$ & $0 \cdot 1$ & $11 \cdot 0-29 \cdot 0$ \\
\hline prs -29 & $0.04-0.08$ & $2 \cdot 0-3 \cdot 0$ \\
\hline prs -40 & ND & $14 \cdot 0$ \\
\hline prs -29 prs -13 & $<0.01$ & $<0.01$ \\
\hline prs -29 prs -26 & $<0.01$ & $<0.01$ \\
\hline prs -40 prs -26 & ND & $5 \cdot 0$ \\
\hline
\end{tabular}

prs-3 with prs-26 were identified, suggesting that the secretion level of this combination did not differ from that of the respective single mutants. By contrast, the combination of prs- 29 with either prs-26 or prs-13 had dramatic effects on the phenotype. Firstly, the growth pattern differed from that of the wild-type in a manner not seen in any single prs mutants or any other combinations of two mutations (Fig. 4). In the exponential phase of growth the double mutants were identical to the single mutants, but they then abruptly stopped growing (Fig. 4); $6 \mathrm{~h}$ later, they resumed growth, so that the overnight densities were identical to that of the wild-type (not shown). Secondly, in the early stationary phase there was an approximately 1000 -fold decrease of $\alpha$-amylase secretion in these double mutants compared with each single mutant. This decrease was already clear by mid-exponential phase (100 Klett units) when the growth of the double mutants was still indistinguishable from that of the single mutants (Fig. 4). 


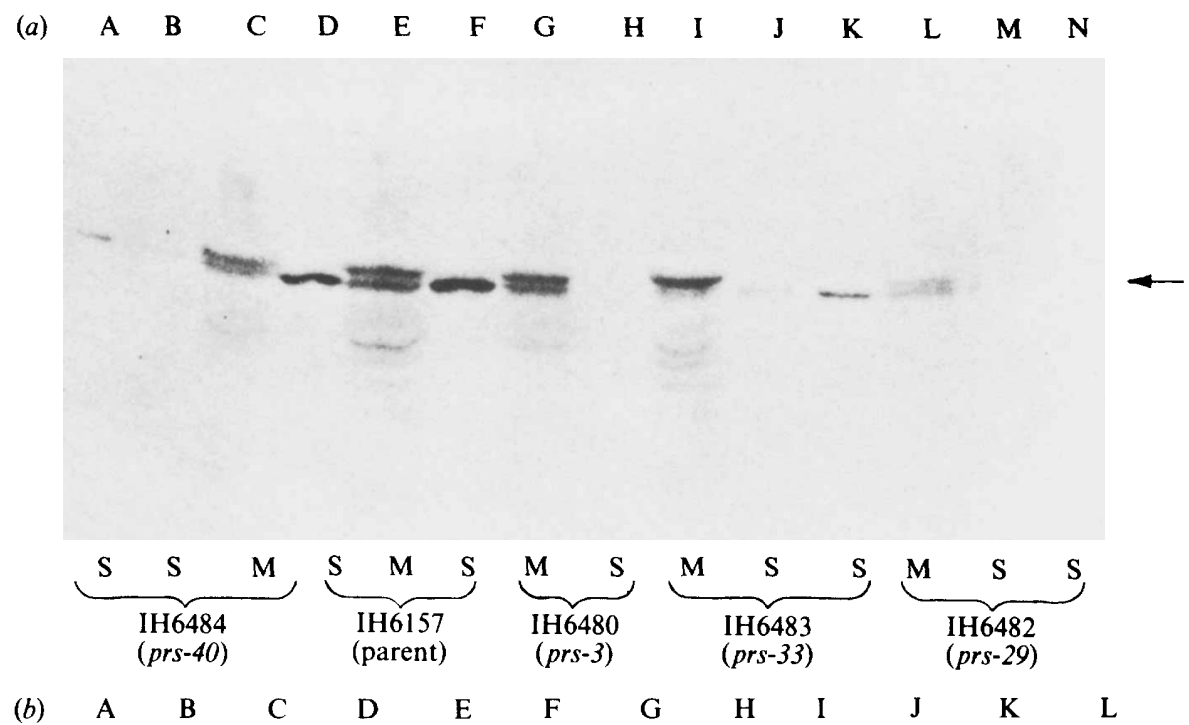

$\begin{array}{llllllllllllll}\text { (b) } & \text { A } & \text { B } & \text { C } & \text { D } & \text { E } & \text { F } & \text { G } & \text { H } & \text { I } & \text { J } & \text { K } & \text { L }\end{array}$

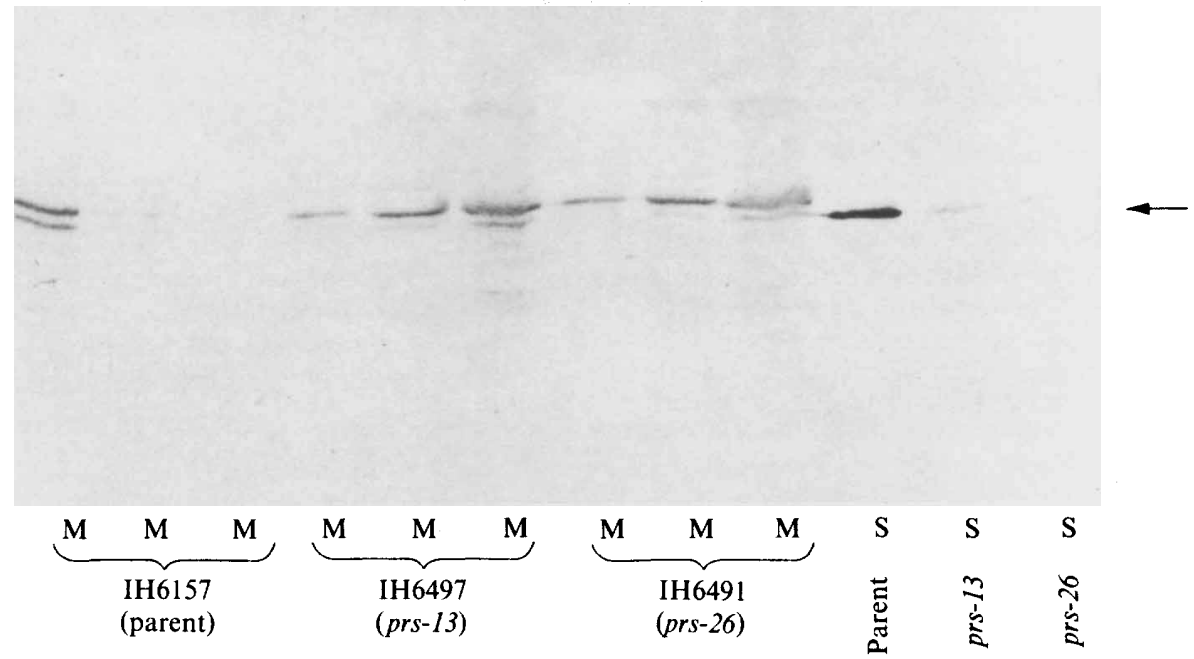

Fig. 5. SDS-PAGE and immunoblotting with rabbit antiserum against $\alpha$-amylase of $B$. amyloliquefaciens. Culture supernatant (S) and cell membrane fraction (M) of different prs mutants in early stationary phase (6 h after $100 \mathrm{Klett}$ units) were analysed. (a) The amount of membrane fraction was from bacteria in $1 \mathrm{ml}$ of culture; the amount of culture supernatant was $10 \mu \mathrm{l}$ in lanes $\mathrm{A}, \mathrm{F}, \mathrm{H}, \mathrm{K}$ and $\mathrm{N}$, and $5 \mu \mathrm{l}$ in lanes B, D, J and M. Staining was with ${ }^{125} \mathrm{I}$-labelled protein A from Staphylococcus aureus. The arrow indicates exoamylase. (b) The amount of membrane fraction was from bacteria in $0.9 \mathrm{ml}$ of culture in lanes $\mathrm{F}$ and $\mathrm{I}$; in $0.3 \mathrm{ml}$ of culture in lanes $\mathrm{A}, \mathrm{E}$ and $\mathrm{H}$; in $0.1 \mathrm{ml}$ of culture in lanes $\mathrm{B}, \mathrm{D}$ and $\mathrm{G}$; in $0.03 \mathrm{ml}$ of culture in lane $\mathrm{C}$. The amount of culture supernatant was $5 \mu \mathrm{l}$ in lanes $\mathrm{J}, \mathrm{K}$ and $\mathrm{L}$. Other designations as in $(a)$.

\section{Immunoblots of the prs mutants}

A block in the secretion pathway might cause cellular accumulation of the secretory proteins or their precursors. We therefore studied the possible accumulation of $\alpha$-amylase in the prs mutants by SDS-PAGE followed by immunoblotting with anti- $\alpha$-amylase serum. Fig. 5 shows that the anti- $\alpha$-amylase serum recognized one protein of $55 \mathrm{kDa}$ in the culture supernatant and two major proteins of 58 and $55 \mathrm{kDa}$ in the cell membrane of an $\alpha$-amylase-producing parent strain. None of these proteins was seen in preparations of IH6064, which does not produce $\alpha$ amylase (not shown). The larger of the membrane-bound proteins is of the size of the in vitro 


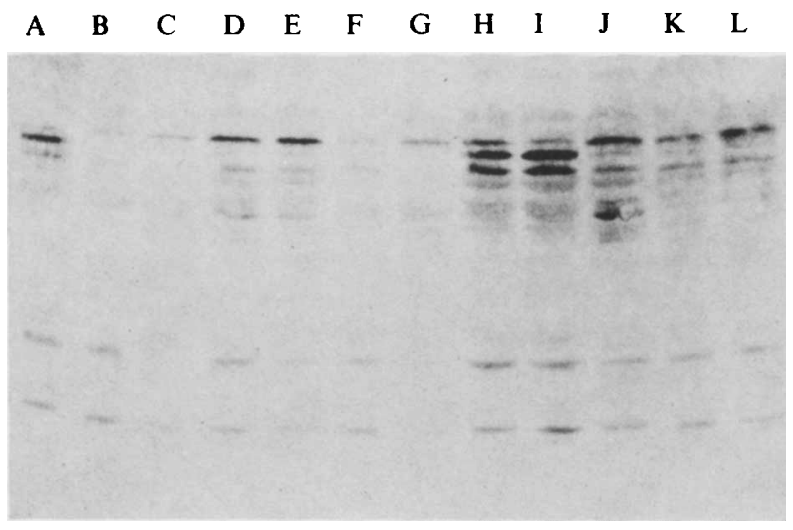

Fig. 6. Comparison of $\alpha$-amylase in the membrane fractions of single and double prs mutants. Cultures were sampled in the early stationary phase $(6 \mathrm{~h}$ after $100 \mathrm{Klett}$ units) unless otherwise indicated. Membrane preparations ( $3 \mu \mathrm{l}$, concentrated 100 -fold) were electrophoresed in SDS-PAGE and immunoblotted with anti- $\alpha$-amylase serum. Lane A, $\alpha$-amylase of IH6527 (prs-29); lanes B and C, double mutant IH6550 (prs-29 prs-26), at 100 Klett units and 6 h later, respectively; lane D, IH6521 (prs-26); lane E, IH6522 (prs-13); lanes F and G, double mutant IH6551 (prs-29 prs-13) at $100 \mathrm{Klett}$ units and $6 \mathrm{~h}$ later, respectively; lane H, IH6513 (wild-type); lane I, IH6525 (prs-3); lane J, IH6529 (prs33); lanes K and L, double mutants IH6533 (prs-33 prs-3) and IH6534 (prs-33 prs-29). The arrow indicates the exoamylase-like protein.

precursor (Palva, 1982) of $\alpha$-amylase, and is most probably the precursor form from which the signal peptide has not been cleaved. The $55 \mathrm{kDa}$ membrane-bound protein has the same molecular mass as the purified exoamylase, and may represent exoamylase trapped in the cell membrane preparation or a degradation product of the $58 \mathrm{kDa}$ precursor.

Four of the prs mutants (prs-3, prs-29, prs-40 and prs-11) resembled the parent strain in containing $\alpha$-amylase proteins of 58 and $55 \mathrm{kDa}$ in the membrane preparations (pattern 1) (Figs 5 and 6; data for prs-11 not shown). Membrane preparations of mutants prs-33, prs-13 and prs-26 contained only the $58 \mathrm{kDa}$ precursor of $\alpha$-amylase (pattern 2, Fig. 5).

In each case, the amount of $\alpha$-amylase in the supernatant (visually estimated on the immunoblots) was much less than that in the supernatant of the parent, confirming the data of the enzyme assays (Table 2). The size of the $\alpha$-amylase in the supernatant was $55 \mathrm{kDa}$ in each case, indicating that processing had taken place.

We also tried to make quantitative estimates of the $58 \mathrm{kDa}$ precursor from the immunoblots. Titration of membrane preparations derived from $0.3-0.03 \mathrm{ml}$ of the culture of the wild-type showed that the detection limit of the $58 \mathrm{kDa}$ band in the blot was between 0.3 and $0.1 \mathrm{ml}$ of culture (Fig. 5 b). In all mutants the $58 \mathrm{kDa}$ protein was clearly visible in blots made from $0.3 \mathrm{ml}$ of culture. When membrane preparations of mutants prs-13 and prs-26, both of pattern 2 , were titrated, the $58 \mathrm{kDa}$ protein was still detectable in preparations from $0 \cdot 1 \mathrm{ml}$ of culture, suggesting a relative increase of the precursor in these mutants compared to the parent. In the double mutants combining mutations producing pattern 1 and mutations producing pattern 2 , both the banding pattern and the amount of precursor were similar to pattern 2 (Fig. 6).

\section{DISCUSSION}

Screening for mutations with decreased secretion of $\alpha$-amylase produced mutations in four chromosomal loci, designated prs. All these mutations were pleiotropic and decreased the secretion of several exoproteins. Thus they either affect the protein export machinery or the transcriptional regulation system of exoprotein genes (Shimotsu \& Henner, 1986; Aymerich et al., 1986; Yang et al., 1987). We consider the first alternative to be more likely for the following reasons. Firstly, the decrease in the amount of exoamylase, to $2-15 \%$ of the parental level, was not paralleled by a decrease of the membrane-bound precursor. Secondly, in some of the 
mutants, decreased exoprotein levels were seen only in the presence of the plasmid pKTH10 (Table 2), when the amyE gene is very highly expressed (Palva, 1982). Thus the pleiotropic effect of these prs mutations seems to require a relatively high overall level of protein secretion.

Impaired secretion of exoproteins might also affect the structure of the cell wall, which is itself synthesized by exported proteins. Indeed, some prs mutants had properties suggestive of such effects (Table 3). The prs-29 mutant formed small colonies, but only in the presence of pKTH10 and hence a high level of $\alpha$-amylase secretion. The prs-13,prs-26 and prs-33 mutations conferred non-transformability. The somewhat decreased ability of many prs mutants to sporulate may also be due to alterations of the cell wall as a consequence of the secretion defect. The prs mutations did not map in known spo loci. Only two of the secretion defective mutations (prs-13 and prs-26, linked to $g l y B$ ) mapped close to a sporulation locus, $s c o C$, and the phenotype of $s c o C$ mutants (Milhaud et al., 1978) is very different from that of the prs mutants.

The prs mutations mapped in four distinct chromosomal loci and prs mutations in each of the four loci caused a characteristic secretion phenotype, including two patterns of accumulation of $\alpha$-amylase precursor (Fig. 5) and distinctive effects on the release of lipopenicillinase (Table 2). Some of the mutations also had clearly additive effects. The combination of prs- 29 with prs -13 or prs-26 decreased the amount of secreted $\alpha$-amylase about 1000 -fold compared to each mutation alone. prs-33 combined with prs-3, prs- 29 or prs-40, all linked to gly $B$, also decreased the level of secretion below that of the single prs mutants. These findings suggest that the four types of prs mutations affect different components of the secretion machinery. Furthermore, the prs-11 mutation was hypostatic to both groups of prs mutations near $g l y B$ and its effect on the release of penicillinase was unique and very unexpected. This might indicate that some components of the secretion mechanism are specific for certain types of proteins.

Mutant genes ( $s a c U, s a c Q, h p r, p r t)$ that have pleiotropic effects on the expression of exoproteins have recently been described in $B$. subtilis. They all increase initiation of transcription of several exoproteins at the promoter level (Shimotsu \& Henner, 1986; Aymerich et al., 1986; Henner et al., 1988; Yang et al., 1987). The prs-11 and prs-33 mutations mapped at loci far removed from these genes. Only the prs genes linked to glyB map close to the hpr gene (Higerd et al., 1972). Our mapping data do not allow conclusions of possible identity of hpr with the glyB-linked prs genes. However, the phenotype of the prs mutants, especially the accumulation of $\alpha$-amylase precursor, the pleiotropy only in the presence of high $\alpha$-amylase production, and the presence of two prs loci near $g l y B$, are not compatible with previously described hpr mutations.

We are grateful to Dr P. H. Mäkelä for critical reading of the manuscript and to the Sigrid Juselius Foundation for financial support.

\section{REFERENCES}

Anagnostopoulos, C. \& Spizizen, J. (1961). Requirements for transformation in Bacillus subtilis. Journal of Bacteriology 81, 741-746.

Aymerich, S., Gonzy-Treboul, G. \& Steinmetz, M. (1986). $5^{\prime}$-non-coding region $s a c R$ is the target of all identified regulation affecting the levansucrase gene in Bacillus subtilis. Journal of Bacteriology 166, 993998.

Dedonder, R. A., LePesant, J.-A., Lepesant-KeJZlarova, J., Billault, A., Steinmetz, M. \& Kunst, F. (1977). Construction of a kit of reference strains for rapid genetic mapping of Bacillus subtilis 168. Applied and Environmental Microbiology 33, 989-993.

EmR, S. D., Hanley-Way, S. \& Silhavy, T. J. (1981). Suppressor mutations that restore export of a protein with a defective signal sequence. Cell 23, 79-88.

Evans, E. A., Gilmore, R. \& Blobel, G. (1986). Purification of microsomal signal peptidase as a complex. Proceedings of the National Academy of Sciences of the United States of America 83, 581-585.

Gilmore, R., Walter, P. \& Blobel, G. (1982). Protein translocation across the endoplasmic reticulum. II. Isolation and characterization of the signal recognition particle receptor. Journal of Cell Biology 96, 470-477.

Gryczan, T., Contente, S. \& Dubnau, A. (1978). Characterization of Staphylococcus aureus plasmids introduced by transformation into Bacillus subtilis. Journal of Bacteriology 134, 318-329.

Henner, D. J., Ferrari, E., Perego, M. \& Hoch, J. A. (1988). Location of the targets of the hpr-97, $\operatorname{sac} U 32(\mathrm{Hy})$, and $\operatorname{sacQ} 36(\mathrm{Hy})$ mutations in upstream regions of the subtilisin promoter. Journal of Bacteriology 170, 296-300.

Higerd, T. B., HoCh, J. A. \& Spizizen, J. (1972). 
Hyperprotease-producing mutants of Bacillus subtilis. Journal of Bacteriology 112, 1026-1028.

ImANAKa, T., Himeno, T. \& Aiba, S. (1985). Effect of in vitro DNA rearrangement in the $\mathrm{NH}_{2}$-terminal region of the penicillinase gene from Bacillus licheniformis on the mode of expression in Bacillus subtilis. Journal of General Microbiology 131, 17531763.

InNis, M. A., Tokunaga, M., Williams, M. E., Loranger, J. M., Chang, S.-Y., Chang, S. \& Wu, H. (1984). Nucleotide sequence of the Escherichia coli prolipoprotein signal peptidase (lsp) gene. Proceedings of the National Academy of Sciences of the United States of America 81, 3708-3712.

Kallio, P., Simonen, M., Palva, I. \& Sarvas, M. (1986). Synthesis of OmpA protein of Escherichia coli K12 in Bacillus subtilis. Journal of General Microbiology 132, 677-687.

Kreibich, G., Ulrich, B. C. \& Sabatini, P. D. (1978). Proteins of rough microsomal membranes related to ribosomal binding. I. Identification of ribophorins I and II, membrane proteins characteristic of rough microsomes. Journal of Cell Biology 77, 464-487.

Meyer, D. I., Krause, E. \& Dobberstein, B. (1982). Secretory protein translocation across membranes the role of the 'docking protein'. Nature, London 297, 647-650.

Milhald, P., Balassa, G. \& Zucca, J. (1978). Spore control (sco) mutations in Bacillus subtilis. I. Selection and genetic mapping of sco mutants. Molecular and General Genetics 163, 35-44.

OLIVER, D. B. \& BECKWITH, J. (1981). E. coli mutant pleiotropically defective in the export of secreted proteins. Cell 25, 765-772.

PaLVA, I. (1982). Molecular cloning of $\alpha$-amylase gene from Bacillus amyloliquefaciens and its expression in Bacillus subtilis. Gene 19, 81-87.

Piggot, P. J. (1985). Sporulation of Bacillus subtilis. In The Molecular Biology of the Bacilli, ppo. 73-108. Edited by D. A. Dubnau. Orlando: Academic Press.

Sarvas, M. \& Nurminen, M. (1985). Polyacrylamide gel electrophoretic analysis of cell envelope proteins. In Enterobacterial Surface Antigens: Methods for Molecular Characterisation, pp. 123-137. Edited by T. K. Korhonen, E. A. Dawes \& P. H. Mäkelä. Amsterdam: Elsevier.

SHImotsu, H. \& HenNer, D. J. (1986). Modulation of Bacillus subtilis levansucrase gene expression by sucrose and regulation of the steady-state mRNA level by sac $U$ and sac $Q$ genes. Journal of Bacteriology 168, 380-388.

SibaKov, M. (1986). Application of a Bacillus secretion vector in protein production. $\mathrm{PhD}$ thesis, University of Helsinki.

Sibakov, M., Sarvas, M. \& Palva, I. (1983). Increased secretion of $\alpha$-amylase from Bacillus subtilis caused by multiple copies of $\alpha$-amylase gene from $B$. amyloliquefaciens is not further increased by genes enhancing the basic level of secretion. FEMS Microbiology Letters 17, 81-85.

Silhavy, T. J., Benson, S. A. \& Emr, S. D. (1983). Mechanisms of protein localization. Microbiological Reviews 47, 3313-3344.

Simons, K., Sarvas, M., Garoff, H. \& Helenius, A. (1978). Membrane bound and secreted forms of penicillinase from Bacillus licheniformis. Journal of Molecular Biology 126, 673-690.

VASANTHA, N. \& FREESE, B. (1980). Enzyme changes during Bacillus subtilis sporulation caused by deprivation of guanine nucleotides. Journal of Bacteriology 144, 1119-1125.

VehmaAnPerä, J. O. \& Korhola, M. P. (1986). Stability of the recombinant plasmid carrying the Bacillus amyloliquefaciens $\alpha$-amylase gene in $B$. subtilis. Applied Microbiology and Biotechnology 23, 456-461.

WALTER, P. (1987). Signal recognition. Two receptors act sequentially. Nature, London 328, 763-764.

Walter, P. \& Blobel, G. (1981). Translocation of proteins across the endoplasmic reticulum. II. Signal recognition protein (SRP) mediates the selective binding to microsomal membranes of in vitro assembled polysomes synthesizing secretory proteins. Journal of Cell Biology 91, 551-556.

Warren, G. \& DobbersteIn, B. (1978). Protein transfer across microsomal membranes reassembled from separated membrane components. Nature, London 273, 569-571.

Wiedmann, M., Kurzchalia, T. V., Hartmann, E. \& RAPOPORT, T. (1987). A signal sequence receptor in the endoplasmic reticulum membrane. Nature, London 328, 830-833.

WOLFE, P. B., WICKNER, W. \& GOODMAN, J. M. (1983). Sequence of the leader peptidase gene of Escherichia coli and the orientation of leader peptidase in the bacterial envelope. Journal of Biological Chemistry 258, 12073-12060.

YANG, M., Shimotsu, H., FerRari, E. \& Henner, D. J. (1987). Characterization and mapping of the Bacillus subtilis prtR gene. Journal of Bacteriology 169, 434437.

Young, F. E. \& WiLson, G. A. (1974). Bacillus subtilis. In Handbook of Genetics, vol. 1., pp. 69-114. Edited by R. C. King. New York: Plenum Press. 